\title{
The Relationship between Availability of Green Space and Comfort Index Based on Remote Sensing Data Analysis
}

\author{
I Ketut Putrajaya ${ }^{1}$, I Putu Hendra Mas Martayana ${ }^{1}$ \\ ketut.putrajaya@undiksha.ac.id
}

${ }^{1}$ Universitas Pendidikan Ganesha, Indonesia

\begin{abstract}
The increasing need for built-up land in Singaraja City has caused a decrease in the quantity of green space. The availability of green space is important to know the percentage of the area and its distribution because it can be related to the environmental comfort index. This study aims to analyze the availability of green space, environmental comfort index, and the relationship between the availability of green space and the comfort index. The main data obtained from Landsat 8 imagery and measurement results. Then the data were analyzed descriptively quantitatively to measure the percentage area of green space based on the NDVI value, the comfort index based on the THI value and linear regression analysis between the two variables. The results obtained indicate that the availability of green space is $50.84 \%$ of the area of Singaraja City which is spread in suburban areas. Most of the comfort levels are categorized as uncomfortable, especially in downtown areas and only a few areas that are categorized as comfortable or comfortable enough are scattered in suburban areas. This is due to the compaction of buildings and activities in the downtown area. The two variables show a significant level of relationship (R2) which is quite strong, which is 0.6299 , but it is necessary to conduct an in-depth study related to other factors that also affect the comfort level of the city. This research is important to do and provide information in addressing urban problems comprehensively.
\end{abstract}

Keywords: Green Space; Comfort Index; Remote Sensing

\section{Introduction}

The development of a region always begins with developments that occur in urban areas. Urban areas are places for the development of social, cultural and economic activities in which there is a concentration of a number of residents as actors [1]. An urban development characterized by the development of the human population that accompanied the physical infrastructure such as housing, transportation, industry, and so serves as a supporting activity of the population in the city is also experiencing growth [2].

The development of an urban area has caused changes in land use which have an impact on the existence of green space as one of the city's ecosystems to be less attention, although the existence of green space is expected to overcome environmental problems and the level of comfort in urban areas [3]. In the early stages of urban development, most of the land is green space. However, with the increasing need for space and land to accommodate population and 
activities, causes the space open green-prone conversion of land into developed regions. The increase in land demand can be seen from two main phenomena in urban areas, namely the expansion of built-up areas in non-built areas and the occurrence of building densification in builtup areas [4].

Singaraja City is part of the administrative area of Buleleng Regency. Although it is not a big city, Singaraja City continues to develop dynamically. Singaraja City is also often referred to as a student city because there are public and private universities whose students come from various districts in Bali and some are from outside Bali. This condition has implications for the development of infrastructure development to support student activities during their stay in Singaraja City such as residences or boarding houses, restaurants, shopping centers, recreation areas and so on. This causes changes in land use from green vegetation cover to built up land, and it is feared that it will affect the quality of the living environment and the level of comfort. [5] suggests that the arrangement of a sustainable urban environment is very important. Availability vegetation in urban planning is necessary to maintain a balance of high air pollution levels so that the necessary efforts for the development of environmental sustainability and comfort level.

Green space, hereinafter abbreviated as green space, is an elongated/ lane and/ or clustered area whose use is more open, where plants grow, both those that grow naturally and those that are intentionally planted (RI Law No. 26 of 2007 concerning Spatial Planning). Referring to these regulations, the development of green space is an important thing to do. The proportion of $30 \%$ is stated as a minimum measure to ensure the balance of the ecosystem [6]. This is of course still relative, so it needs to be studied in depth, especially with regard to aspects of the function and benefits of green space. Green space has a function that can support the creation of a favorable environment, including ecological, social, economic, architecture as well as for the improvement of micro-climate which can affect the level of environmental comfort [3]. The comfort level of the environment can be assessed based on the state of air temperature and humidity. Conditions of air temperature and humidity can be viewed from the presence of vegetation factors, such as tree density, canopy height, and canopy area [2].

Fast and accurate monitoring is needed to determine the availability of green space in an area. Information from remote sensing satellite images will be faster and more efficient about the location, distribution and area of green space which is very helpful in development planning. The availability of Landsat 8 Satellite Imagery which has a spatial resolution of 30 meters has opened up opportunities to obtain information on the characteristics of the availability of green space [7]. Landsat 8 imagery has not been widely used by the government at the district /city level to map the natural resources in an area, so this is another consideration in conducting this research. Remote sensing data processing is expected to be able to provide information quickly and accurately related to the characteristics of the availability of green space that can be used for urban area development planning [8].

The analysis of remote sensing data that will be developed in this study is the transformation of the vegetation index which will produce a value called the vegetation index value. The vegetation index value is a value generated through an algorithm or mathematical equation from several bands (channels) contained in remote sensing data [9]. The vegetation index used in this study is NDVI (Naturalized Difference Vegetation Index), so the band or channel used is the red band (visible) and the near infrared band (near infrared). The value of the vegetation index can provide information about the percentage of vegetation cover, the index of living plants 
(Leaf Area Index), plant biomass, fAPAR (fraction of Absorbed Photosynthetically Active Radiation ), photosynthetic capacity and estimated absorption of carbon dioxide (CO2) [10].

The main objective of this study was to analyze the availability of green space in the city of Singaraja, analyze index of environmental comfort in the city of Singaraja, and analyze the relationship between the availability of green space and comfort index of Singaraja.

\section{Method}

This research was conducted in Singaraja City which is located between $08^{\circ} 03^{\prime} 40^{\prime \prime}$ $08^{\circ} 23^{\prime} 00^{\prime \prime}$ South Latitude and $115^{\circ} 25^{\prime} 55^{\prime \prime}-115^{\circ} 47^{\prime} 28^{\prime \prime}$ East Longitude. The area of Singaraja City is $27.89 \mathrm{~km}^{2}$. Consists of 18 villages, Banyuasri, Kaliuntu, Kampung Anyar, Kampung Bugis, Kampung Kajanan, Kampung Baru, Banjar Bali, Banjar Jawa, Banyuning, Astina, Kendran, Kampung Singaraja, Liligundi, Paket Agung, Banjar Tegal, Beratan, Penarukan, Sukasada, and Baktiseraga.

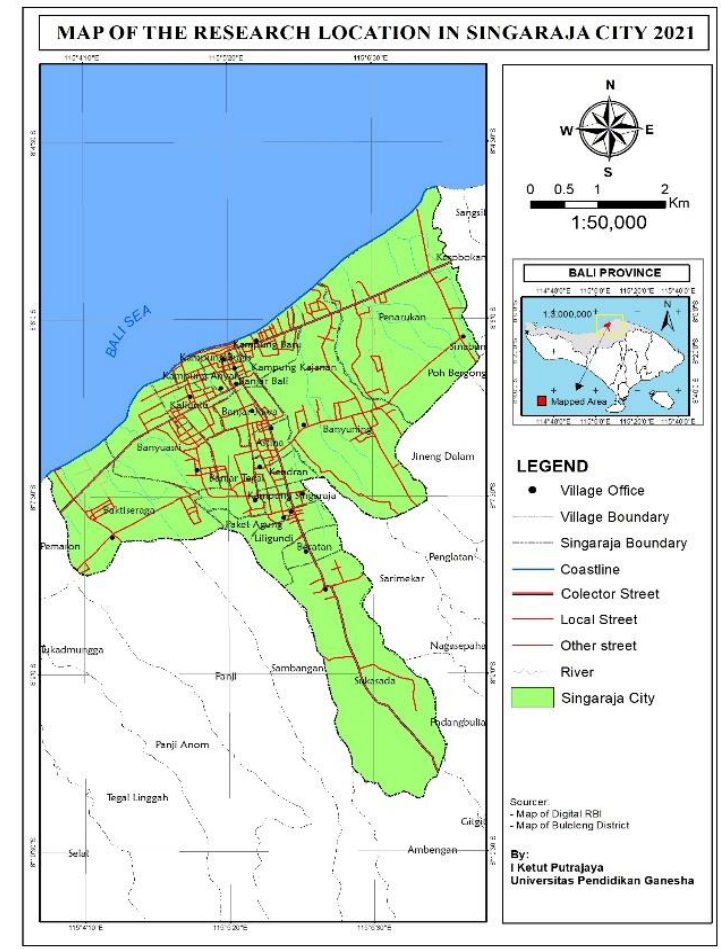

Figure 1. Research Location in Singaraja City

The data used are Landsat 8 OLI imagery for vegetation density extraction, RBI Digital Maps and supported by secondary data and field check results. The data analysis method used is quantitative descriptive analysis to measure the percentage of the presence of green space, the comfort index of the THI method and the correlation between the two variables. Spatial analysis was carried out on a city unit consisting of several kelurahan as a unit of analysis to analyze the 
availability of green space, the comfort index, and the relationship between green space availability and the comfort index. Furthermore, to clarify the data collection techniques and data analysis techniques carried out can be seen in the following description.

The availability of green space is analyzed based on vegetation density because there is a close relationship between vegetation density and the availability of green space [11]. The higher the availability of green space, the higher the oxygen production. This study uses a vegetation index, namely NDVI (Normalized Difference Vegetation Index). The similarities between the two vegetation indices are:

$$
\mathrm{NDVI}=\frac{\rho_{2} \rho_{1}}{\rho_{2}+\rho_{1}}
$$

Information:

$p_{1}=$ red band

$p_{2}=$ Band Infrared close

The results of the transformation of the vegetation index produce a vegetation density map, which in this study is divided into 3 classes of vegetation density, namely low density, medium density and high density. Each level of vegetation density has a different range of vegetation index values. The higher the range of vegetation index values, the higher the vegetation density. Furthermore, from the vegetation density map, the percentage of the area of each class of vegetation density to the area of research is made [8]. The distribution of vegetation cover in various density classes based on the administration to the village can also be known.

Measurement result data is used to obtain environmental temperature information which is also one of the parameters to determine the level of comfort. The measurement of air temperature and relative humidity that has been done is then measured the index. The level of comfort is known by using the comfort index according to [12] can be obtained by the formula:

Information:

$$
\mathrm{THI}=0,8 \mathrm{~T}+(\mathrm{RH} \times \mathrm{T}) / 500
$$

$\mathrm{T}=$ air temperature $\left({ }^{\circ} \mathrm{C}\right)$

$\mathrm{RH}=$ relative humidity $(\%)$

The calculation formula above can be classified according to the level of comfort according to [12] for low latitude tropical climates, namely:

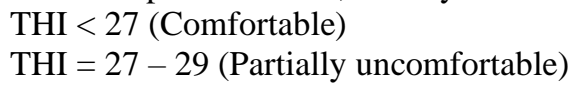

After the availability of the existing green space and the comfort index are determined, then a simple regression analysis is carried out to determine the relationship or correlation of the availability of green space with the comfort index based on temperature and relative humidity.

\section{Result and Discusion}

The determination of the vegetation density class is divided into 3 classes, ranging from low, medium to high vegetation density. The determination of the classification can be further clarified as shown in the following table.

Table 1. Green Cover Based on NDVI Transformation 


\begin{tabular}{rrrrrl}
\hline No. & NDVI Value & \multicolumn{1}{c}{$\begin{array}{c}\text { Area } \\
\mathbf{( H a )}\end{array}$} & $\begin{array}{c}\text { Percentage } \\
(\boldsymbol{\%})\end{array}$ & $\begin{array}{c}\text { Vegetation } \\
\text { Density (\%) }\end{array}$ & \multicolumn{1}{c}{ Category } \\
\hline 1 & $-0,1137-0,2000$ & 934.58 & 40,16 & $<25$ & Non Green Space \\
2 & $0,2001-0,2966$ & 714.90 & 30,72 & $25-50$ & Low \\
3 & $0,2967-0,4334$ & 557.04 & 23,94 & $51-75$ & Medium \\
4 & $0,4335-0,5702$ & 120.69 & 5,19 & $>75$ & High \\
\hline
\end{tabular}

(Source: Data Processing Results, 2021)

Based on Table 1. above, it can be stated that the characteristics of the vegetation density level of Singaraja City are quite diverse, ranging from high density to low density even areas without vegetation. Variations in these characteristics can be explained that the area that is not vegetated has an area of $934.58 \mathrm{Ha}$ or $40.16 \%$ of the area of Singaraja City. Low vegetation density with an area of $714.90 \mathrm{Ha}$ or $30.72 \%$, then medium vegetation density reaching $557.04 \mathrm{Ha}$ or $23.94 \%$, and high vegetation density with an area of only $120.69 \mathrm{Ha}$ or $5.19 \%$ from the area of Singaraja City. The distribution of these figures shows that the area of vegetated areas in Singaraja City is still quite sufficient from $30 \%$ of the requirements for the availability of green space, although it is dominated by low to medium density.

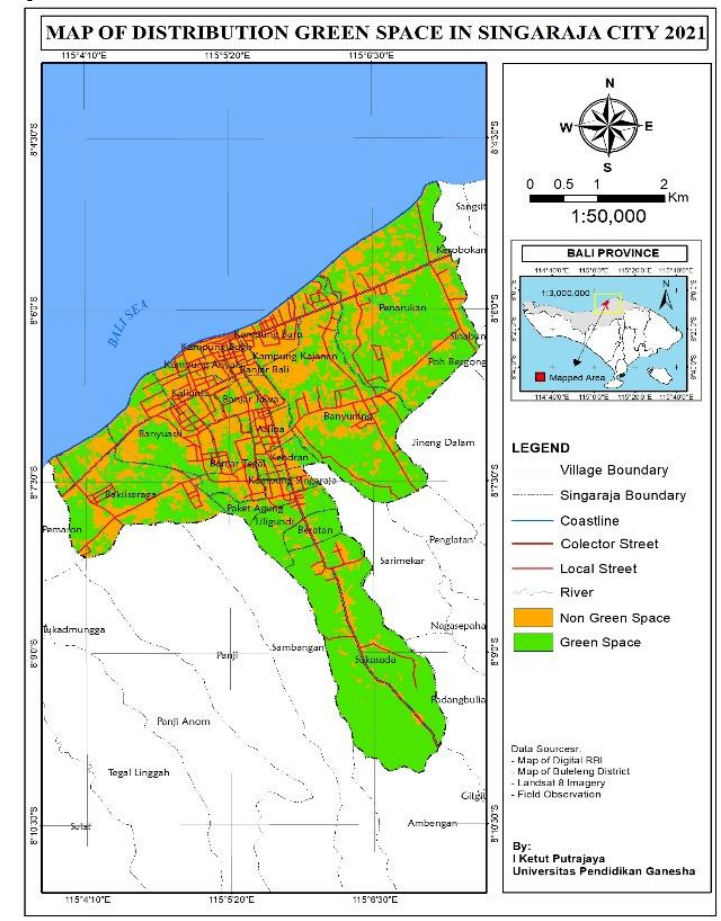

Figure 2. Distribution of Green space in Singaraja City

Based on the picture above, it can be stated that the tendency of green space to spread in suburban areas, while moving towards the city center the presence of green space is increasingly 
limited. This condition occurs due to the concentration of population activities in the downtown area from the education, economic, government sectors, including settlements and other important sectors. This finding was also strengthened in research [13]. The development of some of these sectors certainly requires the availability of land so that this is a trigger for land conversion. This condition will be even more worrying when the land that is converted into built-up land is part of the green space. This needs to be considered, especially regarding the availability of green space and the characteristics of its types so that proper development planning can be carried out. The same thing was said by [14] related to trend of green space.

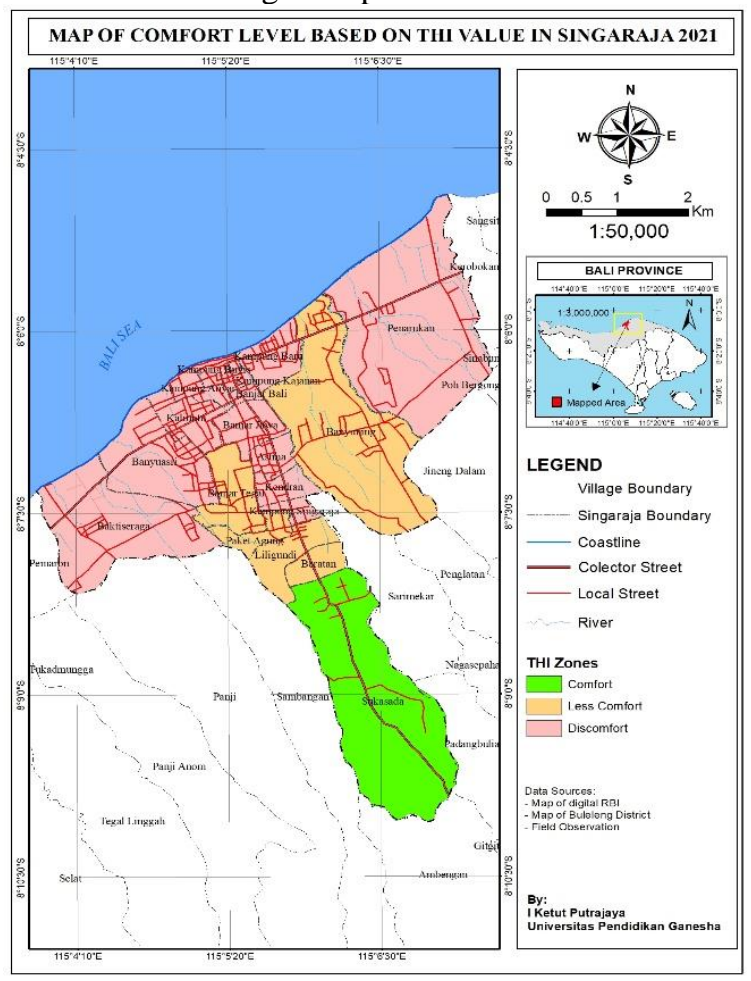

Figure 3. Distribution of the Comfort Level of Singaraja City

Analysis of the level of comfort is also important. The level of environmental comfort through the THI method is based on temperature and humidity measurements. The calculation results are classified into three classes, namely comfortable, partially comfortable, and uncomfortable. The level of comfort in Singaraja City when viewed from the distribution of values, is dominated by the uncomfortable category, namely the THI value $>27$ which is spread in the Singaraja City Center area including Banyuasri Village, Kaliuntu, Anyar Village, Bugis Village, Baru Village, Kampung Kajanan, Banjar Bali, Banjar Jawa, Astina, Kendran, Kampung Singaraja, and several villages on the outskirts of the city such as Penarukan and Baktiseraga villages. This is because the area is the center of population activities, from the government, education, economic, 
health, to distribution sectors. This condition causes the need for development to continue to increase which has an impact on building compaction while the availability of green space is decreasing so that it will indirectly affect climate dynamics, especially with the temperature humidity index which in turn affects the comfort of the people in the area. Furthermore, areas with a partially uncomfortable category with a THI value of 25-27 are spread in suburban areas which include Banyuning, Banjar Tegal, Liligundi, Paket Agung, and Beratan Villages. This can happen due to a reduction in density and an increase in the quantity of vegetation density as in the Vegetation Density Map and the Availability Map of Green spaces in Singaraja City. In addition, the dynamics factor of altitude also affects temperature changes, although it is not too significant for the THI value which is in the range of 26, except in Sukasada Village the THI value reaches 23.65 as well as being the most comfortable village in Singaraja City if it is from the THI value it has. Through linear regression analysis, we can visualize it in the form of a relationship graph.

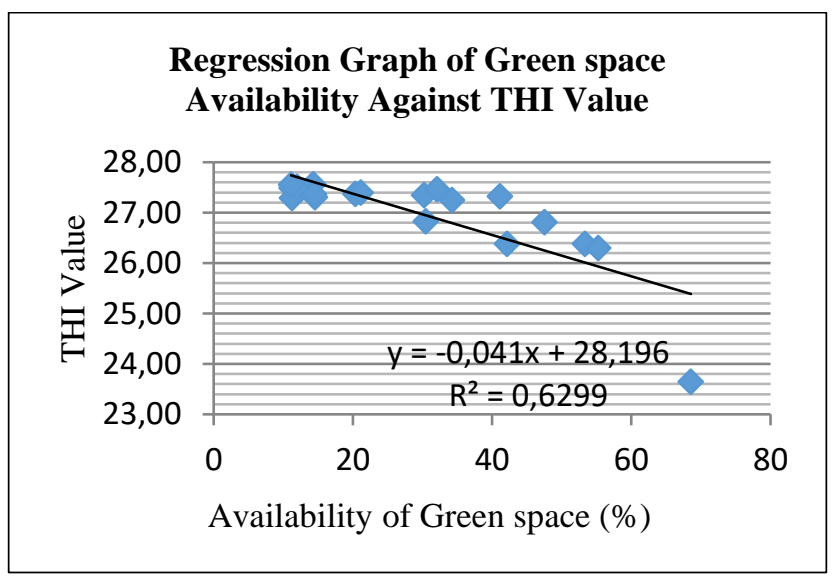

Figure 3. Regression Graph of Green space Availability against THI Value

Based on the picture above, it can be stated that the regression results of the availability of green space and the level of comfort based on the THI value produce a determinant coefficient value $\left(\mathrm{R}^{2}\right)$. The coefficient of the determinant shows the level of significance of a relationship between variables. The value of the determinant coefficient obtained is 0.6299 . This means that the level of the relationship is quite strong but it is necessary to conduct a more in-depth analysis, especially on other variables that also affect the level of comfort considering that the driving factors for the dynamics of comfort in a city are very diverse and depend on the characteristics of each city. Such as research findings [15] found a strong enough correlation.

\section{Conclusions}

The availability of green space in Singaraja City is still quite adequate from the procurement standard requirements according to regulations, but regarding the characteristics of the type it needs attention because the green space for standing vegetation types is very limited which is spatially scattered in suburban areas. Furthermore, the level of comfort in Singaraja City is quite 
varied, although most areas show uncomfortable conditions, especially those approaching the downtown area with various kinds of problems and very few areas that show comfortable conditions. The relationship between the two variables between the availability of green space and the level of comfort shows a fairly strong determinant coefficient but needs to be studied in depth again on other factors that also affect the level of comfort. This research can still be developed further, so it is recommended to choose other data and methods that are more accurate and adapted to the characteristics of the study area in order to obtain better results.

\section{References}

[1] P. R. G. N. . Pussella and L. Li, "Identification and assessment of the driving forces for the use of urban green parks and their accessibility in Colombo, Sri Lanka, through analytical hierarchical processing," Geospat. Health, vol. 4, no. 1, 2019.

[2] J. Alizadeh, B., \& Hitchmough, "A review of urban landscape adaptation to the challenge of climate change,” Int. J. Clim. Chang. Strateg. Manag., vol. 11, no. 2, pp. 178-194, 2019.

[3] I. K. Putrajaya, "Accuracy of alos avnir-2 image technology for mapping oxygen need and green open space priority in denpasar city, bali," J. Eng. Aplied Sci., vol. 13, no. 10, pp. 3594-3600, 2018.

[4] R. Suharyadi, "Hybrid Interpretation of Intermediate Spatial Resolution Satellite Imagery for the Study of Building Densification of Urban Areas in Urban Areas (in Bahasa)," Universitas Gadjah Mada, 2011.

[5] H. Ullah, W. Wan, S. . Haidery, N. . Khan, Z. Ebrahimpour, and T. Luo, "Analyzing the Spatiotemporal Patterns in Green Spaces for Urban Studies Using Location-Based Social Media Data," ISPRS Int. J. Geo-Information, vol. 8, no. 11, p. 506, 2019.

[6] S. H. Atiqul, "Urban Green Spaces and an Integrative Approach to Sustainable Environment," $J$. Environ. Prot. (Irvine,. Calif)., vol. 2, no. 5, pp. 601-608, 2011.

[7] Yuan Fei, "Comparison of Impervious Surface Area and Normalized Difference Vegetation Index as Indicators of Surface Urban Heat Island Effects in Landsat Imagery," Remote Sens. Environ., vol. 106, pp. 375-386, 2007.

[8] A. Zaitimah, Samsuri, A. . Ahmad, and R. . Safitri, "Normalized difference vegetation index (ndvi) analysis for land cover types using landsat 8 oli in besitang watershed, Indonesia," J. Earth Environ. Sci. Conf. Ser., vol. 126, no. 1, pp. 01-09, 2018.

[9] L. E. Icaza, F. van der Hoeven, and A. van den Dobbelsteen, "The urban heat island effect in Dutch city centres," Archit. Built Environ., vol. 7, no. 20, 2017.

[10] A. . As-Syakur, "Vegetation Index Analysis Using ALOS AVNIR-2 Imagery and Geographic Information System (GIS) for Denpasar City Spatial Evaluation (in Bahas)," J. Bumi Lestari, vol. 9, pp. 01-11, 2011.

[11] J. . Jensen, Remote sensing of The Environmental Eagreen open space Resource Perspective. New Jersey-USA: Prentice Hall., 2000.

[12] D. L. Setyowati, "Iklim Mikro dan Kebutuhuan Ruang Terbuka Hijau di Kota Semarang," J. Mns. dan Lingkung., vol. 14, no. 3, 2008.

[13] Liu Ting, "Mapping Vegetation in an Urban Area with Stratified Clasification and Multiple Endmember Spectral Mixture Analysis," Remote Sens. Environ., vol. 133, pp. 251-264, 2012.

[14] R. H. Manan, "Policy Analysis of Urban Green Open Space Management in Jakarta City, Indonesia," Int. J. Enginering Res. Technol., vol. 5, no. 4, pp. 241-248, 2016.

[15] X. Li, C. Zhang, and W. Li, "Does the visibility of greenery increase perceived safety in urban areas? Evidence from the place pulse 1.0 dataset," Isprs Int. J. geo-information, vol. 3, no. 4, pp. 1166-1183, 2015. 